\title{
Id on Line
}

Revista Multidisciplinar e de Psicologia

DOI: $10.14295 /$ idonline.v14i51.2657

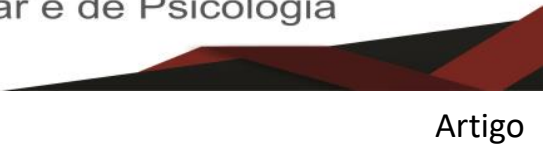

\section{Bairros Negros: \\ Patrimônio Cultural Negro em Fortaleza-CE}

\author{
Tiago Souza de Jesus ${ }^{1}$; Henrique Antunes Cunha Junior ${ }^{2}$
}

Resumo: O presente artigo envereda pelos caminhos de discutir o Patrimônio Cultural Negro, tendo como principal foco a comunidade Rosalina, um bairro negro localizado na Regional VI da cidade de Fortaleza-CE. A presente comunidade tem seu surgimento em 1992, segundo relatos de moradores que, ainda nos dias de hoje, residem na comunidade. Em perspectiva, o bairro negro é uma metamorfose das experiências afrodescendentes em um território. A especificidade das experiências formam estruturas e criam bairros distintos dos demais bairros onde a presença afrodescendente é inferior em relação aos eurodescendente. Por patrimônio cultural negro entendemos tudo que é material e imaterial carregado de valores dado pela sua própria população, à memória, história e cultura afrodescendente. Diante disso, movimentamos conceitos e saberes de intelectuais como: Cunha Junior (2001; 2010; 2017; 2019) Rolnik (2011), Ramons (2013), Munanga (2009), Anjos (2010; 2014). Assim, com a movimentação dos conceitos trabalhado pelos autores eleitos, os percursos urbanos realizados no bairro e as experiências vivenciadas pelas relações estreitas com o bairro estabelecidas por um dos autores, acreditamos alcançar os objetivos do artigo.

Palavras-chave: Bairros negros; Patrimônio Cultural Afrodescendente; Africanidades; Afrodescendência, Ancestralidade.

\section{Black Neighborhoods: Black Cultural Heritage in Fortaleza-CE}

Abstract: This article discusses the Black Cultural Heritage, having as main focus the Rosalina community, a black neighborhood located in the VI Regional of the city of Fortaleza-CE. According to its residents, the community was founded in 1992.In perspective, the black neighborhood is a metamorphosis of Afro-descendant experiences in a territory. This experiences specificities form structures and create neighborhoods distinct from the other neighborhoods where an Afro-descendant presence is inferior in relation to the Euro-descendant. By black cultural heritage is defines as everything that is material and immaterial loaded with values given by its own population, with memory, history and Afro-descendant culture. Therefore, intellectual concepts were gathered and analyzed as per the following sources: Cunha Junior (2001; 2010; 2017; 2019) Rolnik (2011), Ramons (2013), Munanga (2009), Anjos $(2010 ; 2014)$. Thus, through this concepts, the urban routes carried out in the neighborhood and the experiences lived by one of the authors, the goal os this paper was achieved.

Keywords: Black neighborhoods; African Cultural Heritage; Africanities; Afrodescendence, Ancestrality.

\footnotetext{
${ }^{1}$ Especialista em História e Cultura Africana e Afro-brasileira pela Universidade Federal de Goiás. Aperfeiçoamento em Educação, Pobreza e Desigualdade Social pela Universidade Federal do Ceará. Graduado em História pela Universidade Federal de São Paulo. Membro-fundador do NEABI EEMTI Casimiro leite de Oliveira. Professor na SEDUC-CE. E-mail: tiagounifesp@gmail.com;

${ }^{2}$ Pesquisador sobre Populações Negras, História da Tecnológica Africana e Urbanismo Africano. Professor titular da área de engenharia elétrica, pesquisa e ensina sobre Planejamento de Energia e as relações entre Ciência, Tecnologia e Sociedade. Tem formações em engenharia (EESC-USP) e sociologia (UNESP-Araraquara), mestrado em engenharia e mestrado em história. Doutoramente em Engenharia pelo Instituto Politécnico de Lorraine França 1983. Defendeu tese de Livre Docência na Universidade de São Paulo em 1993 e prestou concurso de professor Titular da Universidade Federal do Ceara em 1994. Orientou e co-orientou 25 trabalhos de doutoramento e 46 de mestrados. E-mail: hcunha@ufc.br

1045 Id on Line Rev. Mult. Psic. V.14, N. 51 p. 1045-1059, Julho/2020 - ISSN 1981-1179
} 


\section{O propósito deste estudo}

O presente artigo guarda em seu escopo entender e discutir o bairro negro como patrimônio cultural negro. O bairro negro em questão compõe um território de maioria afrodescendente da cidade de fortaleza, a comunidade Rosalina. Do ponto de vista histórico e social, a Rosalina é território de maioria afrodescendente (JESUS; CUNHA JUNIOR, 2019) e está localizado na Regional VI da cidade de Fortaleza. Nos Território de maioria afrodescendente encontramos múltiplos grupos com diversidade histórica distinta, porém, encontramos também, em sua maioria, os afrodescendentes, responsáveis por dinamizar culturalmente e socialmente o território. (CUNHA JUNIOR, 2007)

Definir a Rosalina como bairro negro significa especificar um bairro dentro de uma diversidade que forma a cidade de Fortaleza. Para Henrique Cunha Junior, nos bairros negros encontramos "os herdeiros despossuídos do passado escravista criminoso, inseridos nos processos de urbanização brasileira do período do pós-abolição e vivendo a materialização do capitalismo racista". (CUNHA JUNIOR, 2019, p. 64)

Para trabalharmos com a Comunidade Rosalina é necessário que façamos fundamentação teórica em conceitos que venham a romper com o eurocentrismo epistemológico, driblando a pobreza interpretativa do pensamento universitário sobre os bairros negros, ao partirem de generalizações e conceituações que pouco ou nada traduzem a realidade afrodescendente em um bairro negro.

A Africanidade permite-nos conceituar a unidade do conhecimento na comunidade Rosalina. Afrodescendência, comunidade e ancestralidade em uma perspectiva de base africana fundamentam a análise da Rosalina. As múltiplas experiências africanas e afrodescendentes na diáspora - marca profunda nos territórios brasileiros — são organizados dentro do conceito de Afrodescendência. Africanidade "marca a unidade do conhecimento" (SANTOS e CUNHA JUNIOR, 2019) e das múltiplas experiências afrodescendentes na diversidade.

Por sua vez, patrimônio cultural negro é um artefato, material ou imaterial, que confere a ele uma memória afetiva de determinado grupo da sociedade, atribuído de valores à sua história, cultura e identidade. Para falarmos de Patrimônio Cultural Negro, é necessário falarmos de memória, que marca a força da afetividade dos afrodescendentes em relação à Comunidade Rosalina. Nesse sentido, "patrimônio cultural da população negra é tudo que confira valor a memória negra, a identidade negra e a produção da história e cultura negra" (CUNHA JUNIOR, 2019, p. 93) 


\section{Historicidade espacial da cultura negra no Brasil}

No mundo atlântico, o Brasil foi o país que mais recebeu em seu território o contingente populacional escravizado, ao longo do período que compreende os séculos XVI e XIX (ALENCASTRO, 2000), "especificamente entre 12 e 13 milhões de seres humanos transportados" (ANJOS, 2010, p. 5). A maioria numérica da população brasileira neste período é, portanto, de africanos desterritorializados (ALENCASTRO, 2000; ROLNIK, 2003), o que nos leva a conclusão difícil de ser aceita por parte da população brasileira de que o Brasil foi colonizado por africanos (CUNHA JUNIOR, 2007).

O território é algo mais amplo que o próprio bairro, nosso foco de estudo neste artigo. Porém, para reconstruir o fio condutor do surgimento dos bairros negros é importante sublinhar o território. Conceitualmente "o território é na sua essência um fato físico, político, social, categorizável, possível de dimensionamento, onde geralmente, o Estado está presente e estão gravadas as referências culturais e simbólicas da população.” (ANJOS, 2010, p. 10)

Os bairros negros são reflexos de pelo menos dois fatores: o gigantesco contingente populacional de africanos sequestrados durante o período do escravismo criminoso e, a as políticas de segregação espacial surgidas no período republicano que deram origem às cidades brasileiras (CUNHA JUNIOR, 2017). Estes dois aliados à políticas higienistas, nortearam a criação de bairros distantes dos centros comerciais, que até então eram habitados em sua maioria por pretos e pardos. Os bairros negros são, portanto, marcas da historicidade espacial brasileira.

Os bairros negros hoje existentes no país são resultados de um longo processo de ocupação territorial iniciado por volta do século XVI, quando da chegada dos primeiros africanos no Brasil. A composição étnica africana formou o que conhecemos hoje como Brasil, imprimindo suas marcas nos territórios, na cultura, nos fazeres sociais diários, na religião, enfim, em todas as dimensões da estrutura social brasileira hoje existente. Isso implica afirmar que a população africana e seus filhos afrodescendentes nascidos no Brasil ao longo do período escravista foram (e são ainda hoje) maioria numérica. (ANJOS, 2010, CUNHA JUNIOR, 2007). 
Especificamente, "a formação de um bairro negro é marcada por um processo histórico das várias expressões de culturas negras que configuram diferentes sociabilidades e espacialidades" (RAMOS, 2013, p. 195). A solidariedade é um dado qualitativo fortemente presente nos afrodescendentes que vivem nos bairros. Essa é a marca profunda que encontramos quando remontamos a história de um bairro negro. A cultura negra, como dito, imprime nos bairros sua marca e dinamiza o espaço. O bairro negro é, portanto, "aquele que predomina a cultura negra" (RAMOS, 2013, p.194).

A solidariedade, como componente de sociabilidade cotidiana na Comunidade Rosalina, construiu o bairro. Abaixo podemos observar uma imagem cedida pela Associação de Moradores da Comunidade Rosalina que nos mostra um registro da solidariedade presente no bairro negro.

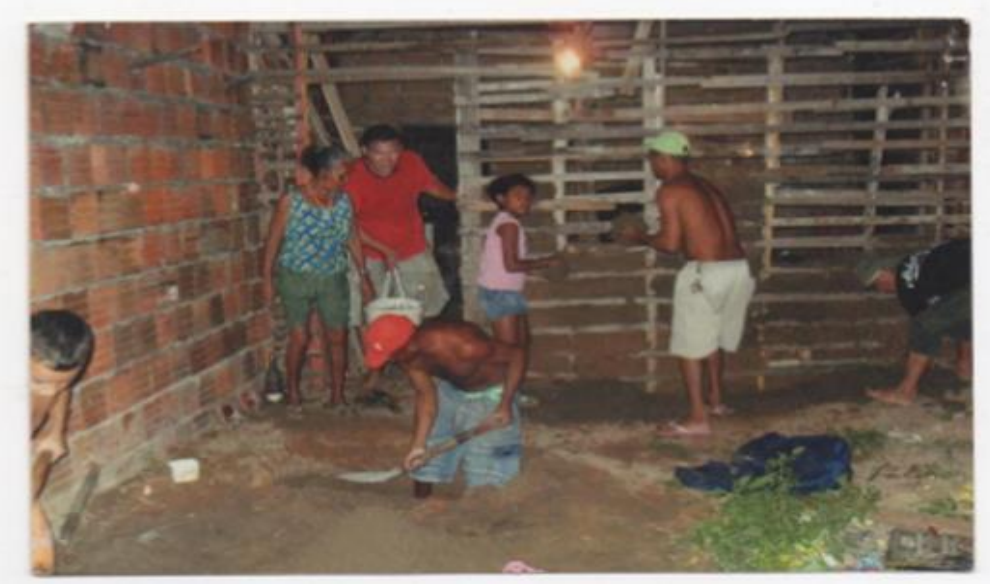

Figura 1: Moradores construindo sua moradia na comunidade Rosalina. Fonte: Arquivo particular da Associação Comunitária da Rosalina, s/d.

Acima observamos as técnicas de construção conhecida como pau-à-pique ${ }^{3}$, técnica esta dentre outras "em uso até hoje, e que foram introduzidas e difundidas no Brasil pelos africanos" (CUNHA JUNIOR, 2010, p. 28) e presente na comunidade Rosalina. Maria Estela Rocha Ramos, sublinha que as estratégias de solidariedade constitui uma história coletiva

\footnotetext{
${ }^{3}$ Essa técnica é conhecida por vários nomes, dentre elas "casas de barro" e "barraco", nomes comumente utilizado pelos moradores da Rosalina.

$1048 \begin{aligned} & \text { Id on Line Rev. Mult. Psic. V.14, N. } 51 \text { p. 1045-1059, Julho/2020 - ISSN 1981-1179 } \\ & \text { Ediçâo eletrônica em http://idonline.emnuvens.com.br/id }\end{aligned}$
} 
afrodescendente que cria as autoconstruções, a partir de saberes dos próprios moradores. Para ela:

\begin{abstract}
“O bairro negro é decorrente de uma história coletiva que explora possibilidades de uma criação autônoma pela forte expressão cultural afro-brasileira, embora condicionada aos contextos brasileiros. Entendemos o bairro negro também como um território construído a partir dos saberes dos moradores fundadores, que construíram, de certa forma, com êxito, estratégias de solidariedade e de relações sociais" (RAMOS, 2013, p. 194)
\end{abstract}

Em sua gênese, historicamente a Rosalina surge a partir de construções coletivas e da solidariedade entre os moradores. Essas são marcas profundas que estão enraizadas no cotidiano da comunidade. (SOUZA, CUNHA JUNIOR, 2019) As ocupações que formam a Rosalina revela como os afrodescendentes se instalam nos espaços criando o que ANJOS chama de "identidades territorializadas resistentes-sobreviventes" (2014, p. 333).

\title{
Metodologia
}

Temos como base norteadora do caminho que devemos seguir neste trabalho a Metodologia Afrodescendente de Pesquisa. Não como uma forma de entendê-la simplesmente capaz de nos guiar para atingir os objetivos, mas por um posicionamento político que nos faz reconhecer que estamos trabalhando de "dentro da própria cultura e com dificuldades que afetam a própria existência” (CUNHA JUNIOR, 2008, p. 75). Nesta metodologia, "consideramos que todos os seres e todos os ambientes contém conhecimento." (CUNHA JUNIOR, 2008, p. 78) Não obstante, “[...] existe um detalhe que é o de reconhecimento e conhecimento de um pensamento de base africana." (CUNHA JUNIOR, 2008, p. 75)

Esse posicionamento político explica que o pesquisador da afrodescendência faz parte do território a ser pesquisado não somente como habitante, de uma forma física, mas também mentalmente. (CUNHA JUNIOR, 2008, p. 75) Ao reconhecermos o pensamento de base africana, entendemos que a ancestralidade e a comunidade são pilares conceituais desse processo. "A ancestralidade nos coloca diante de um fazer da construção do lugar do território dado pelo acúmulo repetitivo da experiência humana", (Idem, p. 76.) enquanto que a "comunidade é vista como a força da identidade pela via da ancestralidade." (Idem, ibdem.)

$\mathrm{O}$ autor afrodescendente Tiago Souza de Jesus residiu na comunidade Rosalina entre Setembro 1998 e Dezembro 2003 e reside atualmente na comunidade, após 16 anos fisicamente 
distante. Seus familiares residem na comunidade desde 1997, o que permite manter relação com a Rosalina sobretudo nos dias atuais em que é membro de um grupo de capoeira e morador.

Os percursos urbanos realizados sistematicamente dentro da comunidade, permitem o pesquisador-morador da comunidade apreender o cotidiano, história e fazer parte dos processos de sociabilidade. As vivências no bairro, o compartilhamento de experiências diárias e as andanças são formas de apreender elementos da vida afrodescendente nos bairros. $\mathrm{O}$ novo conhecimento sobre o desconhecido, tão buscado em pesquisas, deixa de ser o foco na metodologia afrodescendente de pesquisa para dar espaço ao que já é conhecido. Nossa preocupação não com o que está para ser descoberto, mas sim, com que já sabemos sobre nossa própria realidade afrodescendente dentro da comunidade Rosalina.

Entendemos os percursos urbanos como metodologia de pesquisa que permite o pesquisador a "experiência de caminhar e olhar na qual o pesquisador procura não apenas descrever, mas interpretar a realidade" e com isso, "podemos alcançar a consciência espacial das experiências sociais materializadas." (SILVA, CUNHA JUNIOR, 2019, p. 213) Com as andanças, compreendemos elementos antes não percebidos, mas presentes diariamente no espaço habitado. É uma constante revisitação à sua própria casa. A dinâmica territorial afrodescendente permite-nos apreender elementos de base africana, perceptíveis no olhar do pesquisador-morador por meio dos percursos urbanos.

\section{Apresentando o bairro negro}

A Comunidade Rosalina está localizada na Secretaria Executiva Regional VI da cidade de Fortaleza, que conta atualmente com 29 bairros que juntos contabilizam cerca de 600 mil habitantes, sendo a mais populosa e com números de bairros superiores às demais regionais. Tem como vizinho o bairro Parque Dois irmãos e Passaré. Está aproximadamente $10 \mathrm{~km}$ de distância do Centro da cidade e aproximadamente 3,5 km do Aeroporto Internacional Pinto Martins.

A Avenida Bernardo Manoel, importante via de grande tráfego de transportes públicos e particulares e que tem fortes características comerciais, está localizada a cerca de 500 metros de distância da Rua 101, que marca o limite geográfico entre o Parque Dois irmãos e a Rosalina. Esse trecho da comunidade marca também início geográfico das dependências de uma fábrica têxtil, que abrange um quarteirão até a citada avenida. A fábrica chama-se Têxtil Bezerra de Menezes. 
No entorno da comunidade encontramos alguns equipamentos públicos de saúde e educação que consideramos conquistas, ainda que tardias, alcançadas pela comunidade. $\mathrm{O}$ Centro de Educação Infantil Infante Rosalina Rodrigues foi inaugurado em $2013^{4}$. O Posto de Saúde Edilmar Norões, foi inaugurado em $2015^{5}$, já o Centro de Educação Infantil Professor Erasmo da Silva Pitombeira foi inaugurado em $2018^{6}$. As conquista são recentes, visto que a Comunidade surgiu em 1992 e tomou proporções de bairro em 1996.

Além dos equipamentos de saúde e educação, contamos com um ponto de ônibus que liga a comunidade ao terminal urbano de ônibus Parangaba e ao Centro comercial de Fortaleza. No entorno da Rosalina existem também três outros conjuntos habitacionais, sendo eles Riacho Doce, Tupã-Mirim e Conjunto Planalto Itaperi.

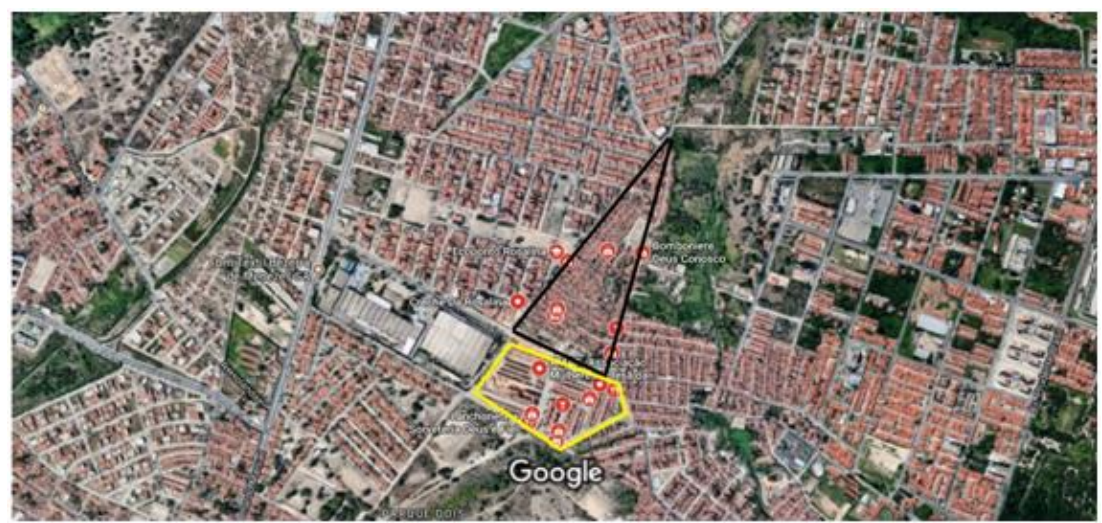

Figura 2: Vista de cima da comunidade Rosalina. Fonte: Google Earth, 2017.

O crescimento vertiginoso dos empreendimentos imobiliários conhecidos como condomínios, sobretudo no bairro Passaré ameaça a comunidade. Esses empreendimentos sufocam o bairro negro, que já não tem mais terreno livre para expansão. Em seu entorno, contamos nove condomínios apenas no bairro Passaré. Esses empreendimentos, no geral

\footnotetext{
4 Segundo o site da prefeitura de Fortaleza, a Instituição de ensino foi inaugurada em 2013. https://www.fortaleza.ce.gov.br/noticias/prefeitura-de-fortaleza-inaugura-novo-centro-de-educacao-infantil-noparque-dois

Inauguração do Posto de saúde Edilmar Norões foi noticiada pelas mídias sociais em 2015: https://diariodonordeste.verdesmares.com.br/metro/posto-de-saude-edilmar-noroes-e-inaugurado-1.1463992

6 De acordo com informações da Prefeitura de Fortaleza, o Centro foi inaugurado em 2018: https://www.fortaleza.ce.gov.br/noticias/prefeito-roberto-claudio-inaugura-centro-de-educacao-infantilprofessor-erasmo-da-silva-pitombeira

1051 Id on Line Rev. Mult. Psic. V.14, N. 51 p. 1045-1059, Julho/2020 - ISSN 1981-1179

Edição eletrônica em http://idonline.emnuvens.com.br/i
} 
cerceiam o livre trânsito ao criar ruas, praças e espaços de lazer privativos, agravando as desigualdades sociais já existentes.

No ano de 2017, aconteceram eleições para escolher a nova liderança da Associação Comunitária da Rosalina. Por sorte (ou por azar, para alguns) Isabel, uma moradora que esteve na ocupação de 1996 venceu as eleições e ainda hoje está à frente da Associação. Dois anos após as eleições, em Fevereiro de 2019, em uma conversa do dia-a-dia com Maria de Jesus, que chegou na comunidade em 1997 com seus dois filhos Thiago e Diego ${ }^{7}$, perguntamos qual a opinião dela em relação a eleição de Isabel. Dona Maria de Jesus respondeu o seguinte em tom de revolta:

Para mim não muda nada! Eu já sei quem ela é e sei bem do que ela é capaz. Uma vez fui lá na Associação perguntar a eles dois o que eles iriam fazer em relação a minha casa que já estava condenada, sendo que eu não consegui nenhuma casa nova no Conjunto Habitacional e eles simplesmente disseram que não poderiam fazer nada. Se eles não podem resolver meu problema que é a moradia, então essa nova gestão da associação para mim é insignificante. Naquela época eu precisava resolver o meu problema que era a moradia e eles não podiam fazer nada. (Maria de Jesus, 2019)

Maria de Jesus é enfática em relação a sua prioridade: a moradia. Essa é a primeira preocupação dos moradores da comunidade Rosalina. A moradia é uma questão fundamental, é mais que a garantia de um teto, é a "possibilidade de acesso aos meios de vida, à água, a toda infraestrutura, à educação, à saúde" (ROLNIK, 2011, p. 38). Todos os percursos urbanos realizados entre Novembro de 2017 e os dias de hoje apontam a questão da moradia como fator como preponderante na vida dos afrodescendentes da comunidade Rosalina.

Essa é a problemática da vida em bairros, e nele estabelecem vínculos, modos de vida coletiva e dinamizam as relações sociais cotidianas. Nesse caminho, constróem identidades, modos de vida, alegrias, tristezas, decepções, criações para solucionar problemas diários, muitos deles decorrentes do racismo antinegro presente na vida urbana do afrodescendentes que vivem em bairros.

Marlene Teixeira e Rosa Machado apresentam-nos o conceito clássico de bairro, segundo a Geografia. $\mathrm{O}$ bairro tem como suporte sua extensão territorial, notadamente marcado pelo lastro histórico das construções, das formas das ruas, que destaca um padrão de vida de uma determinada população. (TEIXEIRA; MACHADO, 1986) No caso da Rosalina, o bairro exerce sua função residencial, com autoconstruções destinadas ao ramo comercial.

${ }^{7}$ Ambos primos do pesquisador-morador Tiago Souza de Jesus

Psic. V.14, N. 51 p. 1045-1059, Julho/2020 - ISSN 1981-1179

Euç̧ăa eletrônica em http://idonline.emnuvens.com.br/íd 
Outro fator fundamental para entendermos os bairros negros sãos as afro-inscrições. Presentes no bairro negro, as afro-inscrições delineiam "as marcas de contribuições de africanos e afrodescendentes de ordem intelectual, técnica, científica, religiosa, de intervenção urbana, de alteração da flora, de modos de produção" (SILVA, 2018, p. 33) presentes na comunidade.

O Brasil apresenta um histórico de políticas higienistas presentes sobretudo hoje na realidade brasileira (SILVA, 2018, p. 33). As políticas higienistas também foram marcas profundas no processo de expansão e modernização da cidade de Fortaleza. A comunidade Rosalina em si é uma afro-inscrição dentro do conjunto de bairros que formam a capital cearense.

\section{Rosalina: patrimônio cultural negro}

Identidade é uma noção em constante transformação. Consciente ou inconsciente, a identidade é mutável e transformável ao longo do tempo e em um dado espaço. Para que essas formações aconteçam, os fatores são os pontos fundamentais para as transformações de um determinado grupo ou indivíduo. Dentro da tríade fator histórico, linguístico e psicológico apontada por Kabengele Munanga que formaria a identidade perfeita, se encontrada a presença simultânea em um grupo ou indivíduo, o fator histórico, segundo ele, é o mais importante, pois "constitui o cimento cultural que une os elementos diversos de um povo através do sentimento de continuidade histórica vivido pelo conjunto de sua coletividade" (MUNANGA, 2009, p. 13)

Em um percurso urbano realizado em Novembro de 2017, no contexto da pesquisa de pós-graduação, o pesquisador-morador Tiago Souza de Jesus foi perguntado por uma das moradoras mais antigas da comunidade qual o interesse em pesquisar a comunidade. $\mathrm{O}$ pesquisador respondeu que tinha o interesse em buscar o fio condutor que ligava a origem da comunidade com aquele dado momento, uma busca pela reconstrução histórica da comunidade. A moradora, com seu cigarro entre os dedos, bateu no peito afirmando "eu moro aqui desde que ela (a Rosalina $)^{8}$ nasceu!”. Em seguida continua: “Quando ela nasceu, só tinha mato e nós trabalhando pra construir os barracos pra morar. Tinham quatro casas e hoje está aí, crescendo e melhorando sem ajuda de ninguém de fora." (sic)

${ }^{8}$ Inclusão nossa.

${ }^{9}$ A conversa foi realizada no dia 28 de Novembro de 2017, em frente a residência da entrevistada, na rua Edson Alves. 1053 Id on Line Rev. Mult. Psic. V.14, N. 51 p. 1045-1059, Julho/2020 - ISSN 1981-1179 
Dois pontos são importantes serem frisados na fala da moradora: a primeira é o fato de sentir-se parte da história da comunidade. No trecho em que a moradora afirma que vive na Rosalina "desde que ela nasceu”, traduz um entrelaçamento histórico entre a comunidade e o indivíduo. O lugar que a Rosalina ocupa na memória da moradora "produz inscrição num território físico e imaginário" (CUNHA JUNIOR, 2019, p. 87) e viabiliza a existência do documento oral, que permite a inscrição do presente texto.

O segundo ponto importante na fala da moradora é o orgulho, o sentimento de fazer parte de algo maior que sua própria individualidade, a coletividade. No trecho em que a moradora afirma que "[...] tinham quatro casa e hoje está aí crescendo [...]", reafirma seu orgulho de ter contribuído pela construção da comunidade. Sua casa própria, patrimônio pessoal, está ligada a algo maior que a própria residência. A sua casa compõe um conjunto de moradias, ruas estreitas e estabelecimentos comerciais que formam a parte física do patrimônio cultural que é a Rosalina.

Seguindo essa linha, o cotidiano, as vivências, o dia-a-dia, os processos educativos, culturais e de sociabilidade, aliados aos espaços de convivências, de religiosidade, comerciais e os quintais formam a Comunidade Rosalina, um patrimônio cultural negro, dotado de valores à sua população, história, cultura e identidade. Os valores atribuídos nessa perspectiva, é o que chamamos de patrimônio cultural negro. (CUNHA JUNIOR, 2019).

Isto posto, o "patrimônio é algo que remete à coletividade, ao anti-individualismo" (SODRÉ, 2002, p. 74). Observamos, a partir de Munanga (2009), Cunha Junior (2019) e Sodré (2002), que o patrimônio cultural negro é constituído pelos elementos comunidade, história, ancestralidade e identidade, sendo esta última "formada e transformada no ciclo da vida, na relação espaço e tempo" (CUNHA JUNIOR, 2019, p. 69) e que tem, além do fator histórico, os fatores culturais, de moradia e profissionais como parte de sua constituição, que traduzem "o sentimento de fazer parte de um lugar, de uma memória lembrada e reavivada" (CUNHA JUNIOR, 2019, p. 70), da Comunidade Rosalina, seu patrimônio cultural.

Por conseguinte, "a comunidade é vista como força da identidade pela via da ancestralidade." (VIDEIRA, 2010, p. 54) A identidade, portanto, é "parte do ser e estar" (CUNHA JUNIOR, 2019, p. 70) na Rosalina. Percebemos uma relação estreita entre espacialidade, identidade e história, regidos e interligados pela ancestralidade. A "ancestralidade nos coloca diante de um fazer da construção do lugar, do território dado, pelo acúmulo repetitivo de experiência humana" (VIDEIRA, 2010, p. 54) 
Dentre os espaços de sociabilidade e que são comuns ${ }^{10}$ a todos, inclusive aos recémchegados na comunidade, está o campo do Palito. O campo do palito data do mesmo período de surgimento da comunidade, sendo possivelmente utilizado pela primeira vez como campo de futebol, após o ano de 1996. Até 2018, foi utilizado como campo oficial de futebol do time de futebol amador da comunidade existente desde 1998 e que hoje em dia utiliza outros campos do entorno da comunidade para realizar seus jogos oficiais, como por exemplo no torneio de favelas de futebol amador, organizado pela Central Única das Favelas (CUFA).

Abaixo vemos imagem de um jogo de futebol ocorrido no dia 24 de Dezembro de 2017, um encontro de torcedores do Ceará e Fortaleza, que congregou jovens das comunidades Riacho Doce $^{11}$ e Rosalina.

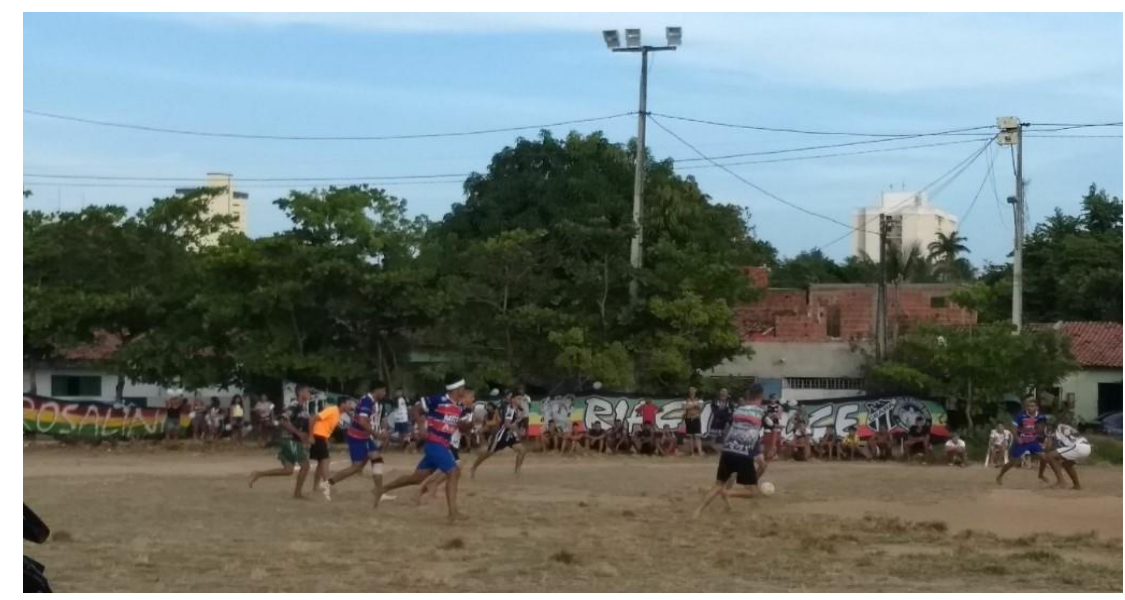

Figura 3: Partida de futebol entre torcedores do Ceará SC e Fortaleza EC, no campo do Palito. Fonte: arquivo pessoal. 2017.

Na fotografia é possível ver um poste com refletores. Este fica em frente a residência de um antigo morador da comunidade e fundador do time de futebol da comunidade. O local constitui-se como um espaço de sociabilidade dentro da comunidade. Local-comum a todos os moradores e dotado de valor simbólico, assim como o campo do palito.

\footnotetext{
${ }^{10}$ Por espaço comum, entendemos os pontos de conhecimento de todos da comunidade: o campo do palito, a casa do mestre de capoeira, a rua Matadouro, a rua 101, a Associação e alguns espaços comerciais. Todos esses tem seu endereço conhecido por todos e comumente recebem grandes volumes de pessoas diariamente. Desses espaços, apenas o campo do palito caiu em desuso e tem sido cada vez menos frequentado, devido alguns crimes ocorridos poucos meses depois do jogo de futebol acima registrado.

11 O Riacho doce é uma comunidade mais antiga que a Rosalina, localizada nos limites dos bairros Passaré e Rosalina, demarcado pela Rua do Matadouro. Existe um histórico de conflitos entre os moradores das duas comunidades em que as torcidas organizadas dos dois clubes de Futebol Ceará SC e Fortaleza EC consideram "um caso sério". 
Abaixo, podemos ver também outro espaço dotado de valor simbólico cultural. Tratase da Associação comunitária: espaço de convivência, realização de cursos, esportes, reivindicações, conquistas e brincadeiras/comemorações em datas festivas. A Associação é uma conquista da Comunidade e teve seu registro realizado, bem como sua fundação no ano seguinte após a grande ocupação ocorrida em 7 de Julho de 1996.

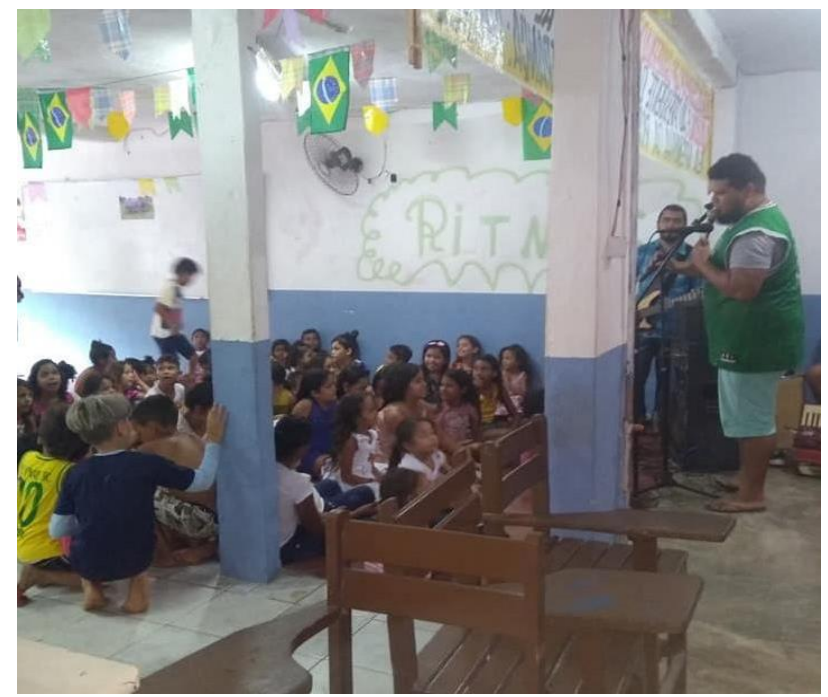

Figura 4: Evento junino para as crianças na Associação Comunitária Rosalina. Fonte: Arquivo particular da Associação. Ano: 2018.

Os espaços são constituídos de valores e estes são ensinados aos mais novos, que aprendem, com os mais velhos, a história do local, bem como os valores patrimoniais da comunidade. Essa é "a razão pela qual cada povo faz esforço para conhecer sua verdadeira história e transmiti-la às futuras gerações.” (MUNANGA, 2009, p. 13) O campo do palito, a casa do dono do time de futebol, a Associação, a casa do mestre de capoeira conferem espaços de valor para a população negra residente na comunidade e formam, assim como os demais espaços aqui não apontados, e os costumes, as vivências e os processos culturais, educativos e de sociabilidades acontecidos no bairro o patrimônio cultural da população negra da Comunidade Rosalina. 


\section{Conclusões}

O patrimônio cultural negro constitui-se como uma lacuna nos estudos acerca dos bairros negros nas cidades brasileiras. Tal lacuna se dê talvez pelo fato de que os patrimônios constituídos socialmente pela maioria da população nacional representa símbolos de interesse à história do país escrita por grupos dominantes. Por conseguinte, o mesmo grupo social que elege tais patrimônios, desconsidera os valores culturais, históricos e identitários dos bairros negros, seu conjunto patrimonial, dado pelos afrodescendentes que vivem neles.

O patrimônio cultural, portanto, necessita não somente da aprovação da população local que mantém uma relação direta com o mesmo. É necessário a aprovação de grupos tidos como dominantes na sociedade brasileira. O não reconhecimento dos valores dados aos bairros negros provocam um campo de disputa protagonizado pela elite dominantes detentora da outorga dos patrimônios versus os despossuídos de tais outorgas, mas possuidores dos valores atribuídos aos seus patrimônios em preservação.

A comunidade Rosalina, portanto, é um patrimônio cultural negro não reconhecido oficialmente pelos donos da outorga oficial. Porém, se mantém em constante preservação pela sua própria população que, capazes de atribuir valor aos espaços de sociabilidade e dinâmica cotidiana do bairro, orgulham-se de fazer parte da história da Rosalina que os une em comunidade e forma as identidades coletivas e individuais. A comunidade Rosalina está, portanto, para a população afrodescendente assim como está o monumento às bandeiras para os eurodescendentes.

\section{Referências}

ALENCASTRO, Luiz Felipe de. O Trato dos Viventes - Formação do Brasil no Atlântico Sul. 1. ed. São Paulo: Companhia das Letras, 2000. v. 1. 525p.

ANJOS, Rafael Sanzio Araújo dos. Geografia do Brasil Africano, O Congo e a Bélgica - Uma Aproximação. Revista Eletrônica: Tempo - Técnica - Território, v. 01, p. 01-25, 2010.

Geografia, cartografia e o Brasil africano: algumas representações. Revista do Departamento de Geografia, v. Especial, p. 332-335, 2014.

CUNHA JUNIOR, Henrique. Espaço Urbano e Afrodescendência. In: CUNHA JUNIOR, Henrique e RAMOS Maria Estela Rocha. (Orgs) Espaço Urbano e afrodescendência. Estudo da espacialidade negra urbana para o debate das políticas públicas. Fortaleza: UFC Edições, 2007 
. Africanidades, Afrodescendência e Educação. Revista Educação em Debate, Ano 23, V. 2 - No. 42, Fortaleza: FACED/UFC, 2001.

Metodologia Afrodescendente em Pesquisa. Ethnos Brasil, v. ano 6, p. 69-80,

2008

Bairros negros: epistemologia dos currículos e práticas pedagógica. In: ANAIS DO COLÓQUIO LUSO-AFRO-BRASILEIRO DE QUESTÕES CURRICULARES, 2017, . Anais eletrônicos. Campinas, Galoá, 2017. Disponível em: $<$ https://proceedings.science/coloquio/papers/bairros-negros--epistemologia-dos-curriculos-epraticas-pedagogica--?lang=pt-br > Acesso em: 18 jul. 2020.

Bairros negros: A forma urbana das populações negras no Brasil. Revista da ABPN, v. 11, Ed. Especial - Caderno Temático: Raça Negra e Educação 30 anos depois: e agora, do que mais precisamos falar? • abril de 2019, p.65-86.

Tecnologia africana na formação brasileira. Rio de janeiro: CEAP, 2010.

FORTALEZA, Prefeitura de. Educação: Prefeito Roberto Cláudio inaugura Centro de Educação Infantil Professor Erasmo da Silva Pitombeira. 2018, disponível online em: $<$ https://www.fortaleza.ce.gov.br/noticias/prefeito-roberto-claudio-inaugura-centro-deeducacao-infantil-professor-erasmo-da-silva-pitombeira> acesso em 15 jul/2020

. Educação: Prefeitura de Fortaleza inaugura novo centro de educação infantil no parque dois irmãos. 2013, disponível online em: <https://www.fortaleza.ce.gov.br/noticias/prefeitura-de-fortaleza-inaugura-novo-centro-deeducacao-infantil-no-parque-dois> acesso em 15 jul/2020.

MUNANGA, Kabengele. Negritude: Usos e sentidos. São Paulo: Autêntica, $3^{\text {a }}$ ed., 2009, 96 p.

DIÁRIO DO NORDESTE. Saúde: Posto de saúde Edilmar Norões é inaugurado. 2015, disponível online em: <https://diariodonordeste.verdesmares.com.br/metro/posto-de-saudeedilmar-noroes-e-inaugurado-1.1463992> acesso em 15 jul/2020.

RAMOS, Maria Estela Rocha. Bairros negros: Uma lacuna nos estudos urbanísticos - Um estudo empírico-conceitual no bairro do Engenho Velho da Federação, Salvador (Bahia). Tese (Doutorado), Versão Provisória - Universidade Federal da Bahia, Programa de Pós-Graduação em Arquitetura e Urbanismo, Salvador, 2013, $283 \mathrm{f}$.

ROLNIK, Raquel. Moradia é mais que um objeto físico de quatro paredes. São Paulo. (Entrevista). Revista E-metropolis, no 05, ano 2, junho de 2011.

SANTOS, Marlene Pereira dos; CUNHA JUNIOR, Henrique (Orgs.) Afro patrimônio cultural [recurso eletrônico] / Marlene Pereira dos Santos; Henrique Cunha Junior -- Fortaleza, CE: Editora Via Dourada, 2019. 331 p.

SILVA, Renata Aquino da. Afroinscrições em petrópolis: história, memória e territorialidades. Tese (doutorado) - Universidade Federal do Ceará, Faculdade de Educação, Programa de Pós-Graduação em Educação, Fortaleza, 2018, 154 f. 
SODRÉ, Muniz. O terreiro e a cidade: a forma social negro-brasileira. Mauad Editora Ltda, 2002.

SOUZA, Tiago.; CUNHA JUNIOR, H. Comunidade Rosalina: um território de maioria afrodescendente na cidade de Fortaleza - CE. In: CUNHA JUNIOR, Henrique; BIÉ, Estanislau Ferreira; et al (Org.). Bairros negros cidades negras. 1ed.Fortaleza: Via Dourada, 2019, v. 1, p. 137-166.

TEIXEIRA, Marlene P. V.; MACHADO; Rosa M. Conceito de Bairro - Unidade Popular ou Técnica? Anuário do Instituto de Geociências - UFRJ: 1986. p. 66-71. Disponível em: <http://www.anuario.igeo.ufrj.br/anuario_1986/vol_10_66_71.pdf>. Acesso em: 18 jul. 2020

VIDEIRA, Piedade Lino. Batuques, folias e ladainhas: a cultura do Quilombo do CRIA-Ú em Macapá e sua educação. 2010. 262f. Tese (Doutorado em Educação) - Universidade Federal do Ceará, Faculdade de Educação, Programa de Pós-graduação em Educação Brasileira, Fortaleza-CE, 2010.

\section{Como citar este artigo (Formato ABNT):}

DE JESUS, Tiago Souza; CUNHA JUNIOR, Henrique Antunes. Bairros Negros: Patrimônio Cultural Negro em Fortaleza-CE. Id on Line Rev.Mult.Psic., Julho/2020, vol.14, n.51, p. 1045-1059. ISSN: 1981-1179.

Recebido: 29/07/2020;

Aceito: 30/07/2020. 